\section{NOVA TELLVS}

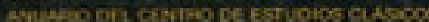

Nova Tellus

ISSN: 0185-3058

novatelu@servidor.unam.mx

Centro de Estudios Clásicos

México

RAMÍREZ VIDAL, Gerardo

El ornatus en la retórica griega clásica

Nova Tellus, vol. 24, núm. 2, 2006, pp. 147-165

Centro de Estudios Clásicos

Distrito Federal, México

Disponible en: http://www.redalyc.org/articulo.oa?id=59120913006

- Cómo citar el artículo

- Número completo

- Más información del artículo

- Página de la revista en redalyc.org

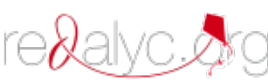

Sistema de Información Científica

Red de Revistas Científicas de América Latina, el Caribe, España y Portugal

Proyecto académico sin fines de lucro, desarrollado bajo la iniciativa de acceso abierto 


\title{
El ornatus en la retórica griega clásica
}

\author{
Gerardo RAMÍREZ VIDAL \\ Universidad Nacional Autónoma de México \\ grvidal@servidor.unam.mx
}

RESUMEN: A pesar de ser considerada una virtus secundaria e innecesaria (frente a lo aptum, la perspicuitas y la puritas, virtutes imprescindibles en todo discurso), el ornatus se convirtió, por un fenómeno sinecdóquico, en la parte central de la retórica, en la esencia misma del arte. En este trabajo pretendo demostrar que ese concepto, entendido como ornamento, como algo agregado al discurso, no existió en la Grecia clásica. Las doctrinas de Isócrates y de Aristóteles indican claramente que los elementos del ornato hacen al discurso "no sólo más agradable, sino también más creíble y convincente". Los tropos y figuras, elementos del ornatus, son cualidades inherentes del lenguaje que el arte retórica reelabora a partir del uso común y corriente, con el fin de dotar al discurso de mayor fuerza persuasiva.

ABSTRACT: Even though it is considered a secondary and unnecessary virtus (if compared with aptum, perspicuitas and puritas, indisputable virtutes in every speech), ornatus turns out, through a phenomenon of synecdoque, to be the central part of rhetoric, the very essence of the art. In this article I intend to show that such a concept, understood in its ornating aspect as something just added to the speech, did not exist in Classical Greece. Isocrates' and Aristoteles' doctrines clearly point out that the ornating elements make the speech "not only more pleasant, but also more reliable and convincing". The tropes and figures, constituent parts of the ornatus, are inherent qualities of language that the rhetorical art re-elaborates from common and daily usage, with the purpose of providing the speech with a more persuasive strength.

Palabras Clave: actio, Aristóteles, discurso, estilo, figuras literarias, Isócrates, ornatus, retórica griega, tropos.

RECEPCIÓN: 22 de septiembre de 2006.

ACEPTACIÓn: 30 de octubre de 2006. 



\title{
El ornatus en la retórica griega clásica
}

\author{
Gerardo RAMíREZ VIDAL
}

Con la palabra ornatus, esto es, ornato, se acostumbra designar a una de las cuatro virtutes elocutionis, o cualidades del estilo. ${ }^{1}$ De estas cuatro virtutes tres son necesarias: lo aptum, que consiste en la adecuación del discurso al destinatario y entre sus partes; la perspicuitas, referida a la claridad que lleva a la comprensión del discurso, y la puritas, que es la corrección idiomática. Por su parte, el ornato no es una virtus necesaria en la tradición retórica, ${ }^{2}$ sino que más bien se le considera como "un lujo del discurso: pretende la belleza de la expresión lingüística" ${ }^{3}$ Ésta es, en resumen, la idea tradi-

\footnotetext{
${ }^{1}$ Los autores antiguos (y modernos) no están de acuerdo en cuántas y cuáles son las virtutes o cualidades del estilo. Aristóteles distinguía, en particular, la claridad; otros autores, sobre todo los estoicos, agregaron otras cualidades, inclu-

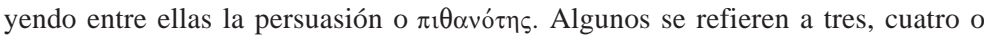
más virtudes. Es el caso, por ejemplo, de Diógenes de Babilonia (o de Seleucia, filósofo estoico, 200-152 a. C.), quien afirmaba: "las virtudes del discurso son cinco: corrección, claridad, concisión, adecuación y artificiosidad. Corrección es un modo de expresión impecable en la técnica y no por una práctica fortuita; claridad es un estilo que muestra de manera patente lo pensado; concisión es un estilo que engloba lo que es propiamente necesario para la exposición del asunto; adecuación es un estilo idóneo al asunto, y artificiosidad es un estilo que evita la

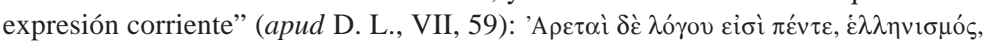

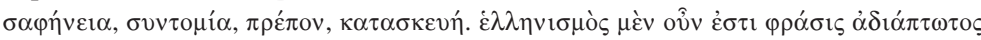

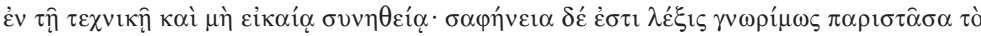

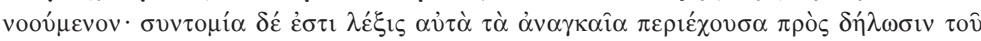

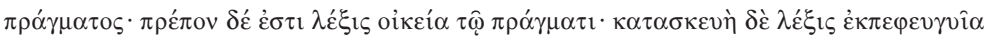

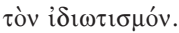

${ }^{2}$ Lausberg, Elementos de retórica literaria, Madrid, Gredos, 1975, § 102.

${ }^{3}$ Lausberg, op. cit., § 162.
} 
cional que perdura hasta hoy acerca del ornato, idea que puede observarse en los términos empleados en las diversas lenguas para referirse a ese concepto. Por ejemplo, en alemán se traduce: Redeschmuck (ornamento), "porque los elementos textuales ornamentales son a menudo considerados sólo como aplicaciones prescindibles". ${ }^{4}$ De tal modo, en virtud de que son un lujo y algo prescindible, se ha pensado naturalmente que lo mejor sería despojar al discurso de dichos elementos ornamentales que degradan la expresión pura del pensamiento.

Sin embargo, ha sucedido todo lo contrario. Esto es, a pesar de ser una parte mínima e innecesaria de la retórica y pese al rechazo de filósofos actuales, el ornatus se convirtió, por un fenómeno sinecdóquico, en la parte central de la retórica, en la esencia misma del arte, tanto que se llegó a confundir a la retórica con la preceptiva literaria. Y, al ser considerada como simple ornatus, se transformó en adorno sin contenido. Por ello, a veces, las alegorías de la retórica son mujeres exageradamente ataviadas y maquilladas, que crean la sensación de superfluidad, artificio, vanidad, engaño, y tantas otras cosas.

Este fenómeno se presenta de manera evidente en los manuales tradicionales de retórica, puesto que se limitan, en gran medida, a registrar, explicar y ejemplificar amplísimos elencos de figuras. Una obra de gran envergadura como los Elementos de retórica literaria de Lausberg resulta paradigmática del peso de la tradición, pues, aunque el autor considera que "el ornatus es un lujo en el discurso", destina 301 parágrafos a las figuras (bajo el subtítulo de ornatus), mientras que dedica tan sólo 69 al resto de la retórica. Lausberg afirma:

El ornatus responde a la pretensión del hombre (tanto del hablante como del oyente) a la belleza en las manifestaciones humanas de la vida y en la autoexposición humana en general.

\footnotetext{
${ }^{4}$ Knape \& Till, “Ornatus”, en HWRh, 6, 2003, coll. 440.
} 
Con lo que el ornatus alcanza, con su intención funcional, la esfera de las artes superiores.

Si las figuras son prescindibles y son un adorno del lenguaje e incluso alteran la adecuada transmisión del pensamiento, entonces no se entiende cómo es posible que esos recursos hayan adquirido tanta importancia frente a lo verdaderamente necesario como lo es la claridad o perspicuitas, y frente a las demás partes de la retórica, la cual sufrió una especie de contracción o desmantelamiento agudo, ante una exagerada ampliación del ornato.

En las páginas siguientes me limito a presentar algunas reflexiones que contienen un balance general de las orientaciones sobre la concepción del ornatus y de la retórica.

Primero: la retórica no es figurática. Como ya se ha dicho, el ornatus es nada más una de las cuatro virtutes o cualidades de la elocución o estilo, junto con la puritas, la perspicuitas y lo aptum. Además de esas cualidades, las reglas de la elocutio consideraban otros elementos, como los diferentes estilos (llano, elevado, fuerte y vigoroso), pero todo esto constituía sólo una de las partes, pues la elocución abordaba fundamentalmente el problema de la composición de las frases o de los periodos. ${ }^{5}$ Así, el ornatus era una virtus secundaria dentro de

\footnotetext{
${ }^{5}$ Dionisio de Halicarnaso dividía la lexis en elección de las palabras y en

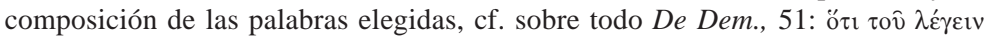

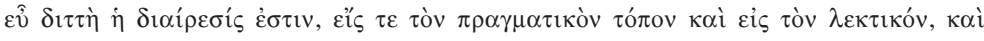

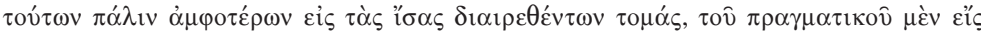

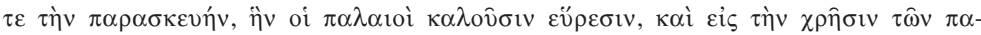

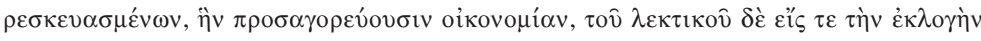

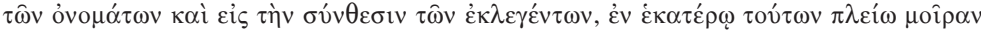

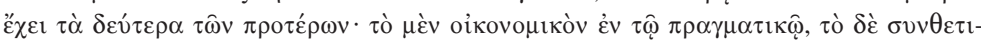

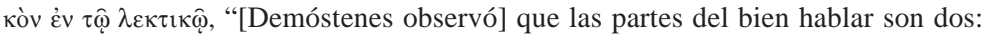
el asunto práctico y el estilo, dividiéndose cada una de ellas en dos partes iguales, el asunto práctico en preparación, que los antiguos llaman invención y en el uso del material preparado, que llaman organización; el estilo, en elección de palabras y en composición de las palabras elegidas, siendo en cada una de ellas
} 
la electio, y ésta a su vez era una de las dos partes de la elocutio, que era una de las cinco partes de la retórica, la cual se ubicaba después de la invención y de la disposición, y antes de la memoria y de la acción o ejecución, a las que se debe agregar la intelección o intelectio, al inicio de todo el sistema retórico.

En pocas palabras, en su origen el ornato era sólo una parte mínima del amplio cuerpo de la teoría retórica, "territorio exiguo, rincón apartado, perdido en la inmensidad de un imperio", según Gérard Genette, ${ }^{6}$ que, sin embargo, llegó a ser considerada como la totalidad de la retórica, al sufrir ésta, como diría Kuenz, ${ }^{7}$ un desmantelamiento o descuartizamiento o estrangulamiento. Hace más de 30 años, Kuenz y Genette llamaron la atención sobre este fenómeno de reducción. Genette, por ejemplo, observa, en relación con la retórica general del Grupo M, que "hemos llegado a titular Retórica general lo que de hecho es un tratado de las figuras", 8 a lo que él denomina figurática y Kuenz, tropología.

Para que las figuras fuesen concebidas como la totalidad de la retórica, y la función de ésta se limitara fundamentalmente al estudio y sistematización de las figuras llamadas "retóricas", hubo un largo recorrido, que inició en época helenística y que todavía conserva vigencia en los estudios actuales de literatura. El campo de lo retórico, afirma Kuenz: ${ }^{9}$

\footnotetext{
más importante las segundas partes que las primeras, esto es, la organización en el asunto práctico y la composición en el estilo". Pero también la dividía en tres: elección de palabras, composición y figuras (cf. De Isoc., 3). Tácito se refiere a la electio inventionis que es la elección de los argumentos descubiertos, y compositionis decor, es decir, la adecuación de la composición. Sin embargo, no existe unanimidad en esta división. En manuales modernos se acostumbra considerar la electio como elección de las figuras y la compositio, como elección de estructuras.

${ }^{6}$ Genette, "La retórica restringida", en Investigaciones retóricas II, Buenos Aires, Tiempo contemporáneo, 1974, p. 203.

7 Kuenz, "Lo 'retórico' o lo puesto al margen", en Investigaciones retóricas II, Buenos Aires, Tiempo contemporáneo, 1974, p. 187.

${ }^{8}$ Genette, art. cit., p. 203.

${ }^{9}$ Kuenz, art. cit., p. 185.
} 
no ha dejado de disminuir, según parece, de Aristóteles a nuestros días [...] Sectores enteros del edificio clásico parecen haberse derrumbado y sólo el prejuicio analítico [...] nos permite llamar todavía retórica a una disciplina reducida a una de sus partes, desarticulada, desconectada: la elocutio, o aun a una parte de esta parte, puesto que no se retiene de ella, en efecto, más que la teoría de los tropos centrada ella misma cada vez más netamente sobre la metáfora.

En sus orígenes, las partes más importantes de la retórica eran la invención y la distribución de las partes. Córax y Tisias aplican a la retórica el عíós, que forma parte de la invención, y avanzaron en el establecimiento de las partes del discurso; Protágoras abordó el estudio de los lugares comunes, que es la parte fundamental de la invención. Es cierto que Gorgias utilizaba un lenguaje sumamente recargado de figuras, pero este tipo de estilo estaba circunscrito a un género particular de obras, aunque al final esto llamó la atención más que su arte inventiva. Aristóteles dedica a la invención las dos terceras partes de su Retórica. Entre la Retórica aristotélica y las retóricas tradicionales de época moderna hay un abismo. Posteriormente, Teofrasto se interesa en el estilo, pero otorga a las figuras un papel muy restringido; al parecer, a él se debe la clasificación cuatripartita de las virtutes. ${ }^{10}$ El escrito de Demetrio Acerca del estilo da cuenta de que dicho campo era muy amplio, y en él las figuras constituyen sólo una parte del estilo. Además, observa: "no se deben usar figuras con abundancia, pues esto es falta de buen gusto y manifestación de una cierta irregularidad del discurso". ${ }^{11}$

\footnotetext{
${ }^{10}$ Cic., Orat., XXIV, 79: unum aberit, quod quartum numerat Theophrastus in orationis laudibus: ornatum illud suave et adfluens, "faltará un solo elemento, que Teofrasto numera en cuarto lugar entre las cualidades del discurso, el ornamento dulce y abundante". Cicerón menciona a Teofrasto al hablar de las virtudes del habla.

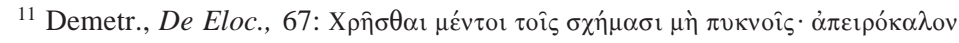

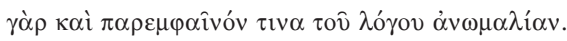


A pesar de todo ello, con el paso del tiempo el enfoque de la retórica se fue limitando cada vez más a las figuras y éstas se fueron multiplicando de manera exagerada. Haberse limitado o haber privilegiado las figuras provocó el grave descrédito de la retórica, a pesar de que se trata de una confusión que tiende a identificar la retórica con las figuras literarias, a tomar la parte por el todo. Lo anterior no quiere decir que se deba expulsar a las figuras de los estudios de retórica. Únicamente se señala que constituían una parte mínima y que su importancia era secundaria.

SEGUNDO: desde el punto de vista retórico, las figuras no valen por sí mismas (causa final o función teleológica de la figura). La retórica se vio reducida no sólo en sentido cuantitativo, sino también en sentido cualitativo al analizarse la figura en sí misma y para sí misma, no como un mecanismo orientado a la persuasión sino al éxtasis. Observemos un ejemplo de esto. En relación con el verso de Virgilio "Ponto nox incubat atra", ${ }^{12}$ traducido como "la negra noche se tiende sobre el mar", Campillo y Correa afirma ${ }^{13}$ que el poeta podría haber utilizado simplemente la palabra anochece para expresar lo anterior:

pero - subraya el autor- ¡cuanta belleza perdería el pensamiento! Porque en la expresión del épico latino vemos la noche, no como la ausencia del sol, sino como un ser animado, misterioso y tan inconmensurable, que cubre con su sombra toda la extensión del piélago, dejándolo en tinieblas.

No importa aquí discutir si Virgilio consideraba la noche como un ser misterioso e inconmensurable, lo cual podría ponerse en tela de juicio, sino destacar que esta interpretación se concluye en sí misma, no atiende a una finalidad externa del

\footnotetext{
12 Verg., Aen., I, 89.

${ }^{13}$ Campillo y Correa, Retórica y poética. Literatura preceptiva, México, Editorial Botas, 1945, p. 173.
} 
texto. Sin embargo, la figura es más que la simple expresión, por más sublime que ésta sea. Tiene esa expresión un efecto práctico en circunstancias específicas. Este fenómeno es bastante claro. Por ejemplo, Albaladejo observa ${ }^{14}$ que

el ornatus, manejado apropiadamente, es un elemento decisivo para el cumplimiento de la compleja finalidad del discurso retórico articulada en delectare, docere y movere [...] En el fenómeno retórico ese deleite hace posible la enseñanza contenida en el texto; es una forma de atracción del receptor para que éste pueda penetrar en la totalidad del texto [...] El discurso artísticamente elaborado en su microestructura capta al destinatario.

Actualmente hay una amplia tendencia a ver en la figura un elemento que produce placer y permite por ello que el emisor transmita con eficacia el argumento al receptor. Las figuras no son, por tanto, un simple adorno, sino un elemento inseparable del lenguaje con una función persuasiva.

Esta característica utilitaria la conocían muy bien los rétores antiguos. Nada más alejado del pensamiento de Isócrates que el ornato por el ornato mismo, aun cuando él mismo hubiera sido considerado como un purista de la prosa. Para el sofista, el discurso en su conjunto posee una función, un épyov, y también las diferentes especies o i $\delta \varepsilon ́ \alpha \iota$, entre ellas las figuras, tienen su propia función dentro del conjunto armónico de la obra. Las minucias estilísticas tienden a crear las cualidades del estilo: claridad, precisión, pureza y belleza, y éstas, a su vez, otorgan a la expresión el poder persuasivo buscado por el autor. En su Filipo, ${ }^{15}$ Isócrates señala que él había enseñado a sus discípulos a escribir con simetrías y variaciones para hacer los discursos más dulces y más convincentes. ${ }^{16}$ Así pues, las figuras existen

\footnotetext{
${ }^{14}$ Albaladejo Mayordomo, Retórica, Madrid, Síntesis, 1991, p. 129.

${ }^{15}$ Isoc., Philippus, 5.

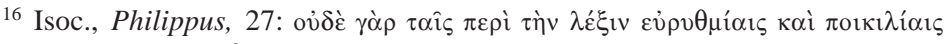

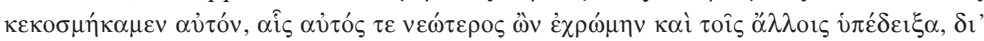


en tanto instrumento de persuasión. Ahora bien, en su época esto era muy conocido por todos: a nadie se le habría ocurrido embellecer por embellecer; pero, en la actualidad, el predominio de la idea del arte por el arte ha oscurecido la antigua concepción pragmático-retórica del estilo y, en particular, de las figuras.

Por su parte, Aristóteles afirma que "no basta con tener lo que hay que decir, sino que también es necesario saber cómo se debe decir, y contribuir en mucho a que el discurso aparezca de un cierto modo", y explica que "para la demostración tiene cierta importancia hablar de éste o de otro modo". ${ }^{17}$ En otras palabras, el estilo tiene como fin la demostración. En el cuarto libro de la Retórica a Herenio se introduce continuamente, al lado de la simple belleza producida por la ornamentación, también los efectos que esta última causa en el destinatario. Así, en cuanto a la exclamación el autor observa que esta figura "aviva la manifestación de dolor o de indignación". ${ }^{18}$ En otro pasaje, presenta el siguiente ejemplo de conduplicatio o anadiplosis: "¿No te conmoviste cuando tu madre se agarró de tus pies? ¿No te conmoviste?”, y enfatiza que la repetición sorprende al auditorio y provoca al adversario una herida más grave, "como si una arma golpeara varias veces la misma parte del cuerpo". ${ }^{19}$ En fin, según el testimonio de

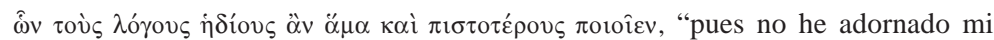
discurso con simetrías y variaciones del estilo, las que había empleado de joven y había enseñado a los demás, mediante las cuales hacía los discursos al mismo tiempo más dulces y más persuasivos".

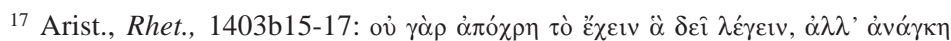

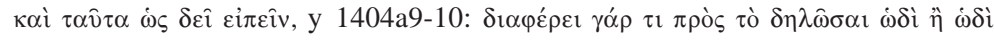

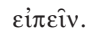

${ }^{18}$ Rhet. ad Herennium, IV, 15, 22: Exclamatio est, quae conficit significationem doloris aut indignationis.

${ }^{19}$ Rhet. ad Herennium, IV, 28, 38: “' Commotus non es, cum tibi pedes mater amplexaretur, non es commotus?' [...] Vehementer auditorem commovet eiusdem redintegratio verbi et vulnus maius efficit in contrario causae, quasi aliquod telum saepius perveniat in eandem partem corporis". 
Séneca el Viejo, Porcio Latrón, un famoso orador contemporáneo del rétor, "Negaba que las figuras hubieran sido como adorno, sino como recurso". ${ }^{20}$

Una figura no puede analizarse fuera de su contexto y sin ver la finalidad que impulsó a utilizarla. Los textos no son objetos de estudio que puedan ser diseccionados en sus elementos mínimos como si se estuviera en un laboratorio, sino que son unidades funcionales dentro de circunstancias particulares, y sus elementos adquieren su justificación y su significación únicamente por su función persuasiva. Los recursos de la elocución tienen por objeto contribuir al proceso persuasivo: dibujar un carácter, crear un ambiente, dominar las pasiones, dejar al auditorio boquiabierto y a disposición incondicional del orador. En un determinado momento del discurso, puede ser adecuada una ironía o una metáfora que funcionen como toques eléctricos en el auditorio; en otros casos, podía haber necesidad de una expresión simple y clara, sin adornos inútiles.

En pocas palabras, el ornatus, independientemente de las funciones que tenga dentro del texto, tiene una finalidad persuasiva.

TERCERO: las figuras son argumentos (causa formal). Existe un razonamiento más que contradice la concepción ornamental de las figuras: la figura como argumento. Perelman y OlbrechtsTyteca, ${ }^{21}$ luego de señalar la tendencia a limitar la retórica al estudio del estilo y de la expresión, y, por lo tanto, a considerar las figuras como simple adorno, se refieren a la communis opinio de que las figuras no cumplen ningún papel en relación con la prueba, y de que en consecuencia no importa si los argumentos se presentan de una u otra manera. Pero ellos objetan al observar que, por ejemplo, en el caso de la hipotiposis

\footnotetext{
${ }^{20}$ Sen., Controv., Praef., 1: "Schema negabat decoris causa inventum, sed subsidii”.

${ }^{21}$ Perelman \& Olbrechts-Tyteca, Traité de l'argumentation. La nouvelle rhétorique, Bruxelles, Presses Universitaires de Bruxelles, 1958, § 41.
} 
(demostratio), esta figura consiste en exponer las cosas de un modo tal que el asunto parece desarrollarse y la cosa pasa ante nuestros ojos o, en otras palabras, es una forma de describir los argumentos que los hace presentes ante nuestra conciencia. Según ellos, no se podría negar el papel eminente de las figuras como factor de persuasión, so riesgo de provocar que el estudio de las mismas se convierta en un pasatiempo inútil.

Desde el punto de vista de la retórica, se debe tomar en consideración en qué casos y cómo el uso de ciertas figuras específicas se explica por la necesidad de argumentación. Así, ambos autores distinguen dos tipos de figuras: las argumentativas, cuando entrañan la adhesión a una nueva situación sugerida (imponer o sugerir una elección, acrecentar la presencia o lograr la comunión con el auditorio), y las ornamentales, cuando el discurso no busca esa adhesión. Por ejemplo, la alusión casi siempre tendrá valor argumentativo, puesto que es esencialmente elemento de acuerdo y de comunión. Por lo que concierne a la sinécdoque, que consiste en decir "los mortales" en vez de "los hombres", es una manera de llamar la atención sobre una característica particular de los hombres. Habrá que subrayar que, para Perelman y Olbrechts-Tyteca no todas las figuras son argumentativas y que las figuras argumentativas pueden observarse también en su nivel puramente ornamental, de modo que, para ellos, sí existe el simple ornamento, aunque muy restringido.

La hipótesis de Perelman y Olbrechts-Tyteca retoma la doctrina de Aristóteles sobre el carácter demostrativo de la figura.

CUARTo: el lenguaje "natural" tiene una naturaleza figurática (causa material). Se ha dicho, se sigue diciendo y se continuará diciendo que el ornato es un fenómeno lingüístico opuesto al lenguaje común, en el cual se basa para adicionarle adornos o colores. Afirma Albaladejo 22 que "los mecanismos del orna-

${ }^{22}$ Albaladejo Mayordomo, op. cit., p. 129. 
tus contribuyen dentro del sistema lingüístico artístico a la configuración de unos tipos de discursos codificados de manera diferente a los de la lengua común". Pero se puede observar que, en realidad, el lenguaje común, esto es, aquel que se habla cotidianamente, está lleno de figuras, de usos retorcidos, de ocultamientos, deslices y olvidos en una proporción considerable. En el lenguaje del mercado es impresionante el uso de figuras: "Pásele, güerita", dice el vendedor a una probable clienta, aunque sea morenita. "La competencia es buena, pero nosotros somos mejores", puede leerse en los anuncios.

En torno a este fenómeno podremos seguir a Nietzsche ${ }^{23}$ y decir que "el lenguaje es retórico" y que

las palabras son en sí y desde el principio, en cuanto a su significación, tropos. En vez de aquello que tiene lugar verdaderamente, presentan una imagen sonora que se evanesce con el tiempo: el lenguaje nunca expresa algo de modo completo, sino que exhibe solamente una señal que le parece predominante.

Acerca de las metáforas señala que, en relación con la montaña, se habla de cima, pie, espalda, gargantas, picos, vetas; en el caso de la metonimia ejemplifica con la expresión "la pócima está amarga", cuando debería decirse "excita en nosotros una sensación particular de esa clase". Y concluye: "Los tropos no se añaden ocasionalmente a las palabras, sino que constituyen su naturaleza más propia". ${ }^{24}$ Esta naturaleza retórica del lenguaje ha sido muy bien estudiada, con base en los autores griegos, por Antonio López Eire, ${ }^{25}$ quien a cada momento parece decirnos, como Genette: "volvamos a lo an-

\footnotetext{
${ }^{23}$ Nietzsche, Escritos sobre retórica, Madrid, Trotta, 2000, p. 92.

${ }^{24}$ Nietzsche, op. cit., p. 93.

${ }^{25}$ López Eire, Acerca del carácter retórico del lenguaje y de cómo los antiguos griegos lo descubrieron, México, Universidad Nacional Autónoma de México (Bitácora de retórica, 21), 2005.
} 
tiguo; será un progreso". Así pues, contra lo que se piensa normalmente, podríamos afirmar que el lenguaje que busca suprimir las figuras es el lenguaje artificial. Pero la supresión de las figuras es imposible. Necesariamente se recurre a nombres como "hoyos negros", "galaxias" y tantas cosas más.

De esta manera llegamos a la conclusión paradójica de que, en realidad, el lenguaje figurado es el natural y de que el lenguaje artificial es el desprovisto de figuras, el que tiene un grado cero, aquel que es neutro. Es difícil probar la existencia de este lenguaje neutro, e inclusive los textos filosóficos y científicos emplean a las figuras, tanto que el filósofo del siglo XIX, Antoine Augustin Cournot, llegó a aseverar que "la lengua de los filósofos no es menos figurada que la de los oradores y los poetas". ${ }^{26}$

Quinto: el lenguaje figurado es, en su origen, propio del verso no de la prosa. Aunque "las palabras son en sí y desde el principio, en cuanto a su significación, tropos", como sostenía Nietzsche, sí existen textos en los que las figuras aparecen conscientemente y consistentemente recargadas, no figuras cuya naturaleza figurativa se ha desgastado, sino figuras que presentan una fuerza figurativa acentuada. Pero éste es un recurso poético, no retórico. Sobre este punto me limito a mencionar a Isócrates. En el Evágoras encontramos un pasaje significativo ${ }^{27}$ donde señala que es más difícil hacer un encomio en prosa que un encomio en poesía, "pues a los poetas

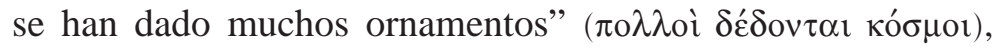
como poder retratar a los dioses conversando con los hombres o ayudándolos en las batallas, cosa que pueden mostrar no sólo con palabras bien ordenadas, sino también con extranjeris-

\footnotetext{
${ }^{26}$ Cournot, Essai sur les fondements de nos connaissances et sur les caractères de la critique philosophique, Paris, L. Hachette, 1912, p. 322. "Et pourtant il est facile de s'apercevoir que le langage des philosophes n'est pas moins que celui des orateurs et des poètes".

${ }^{27}$ Isoc., Evágoras, 8-10.
} 
mos, neologismos, metáforas, y nada dejan de lado, sino que

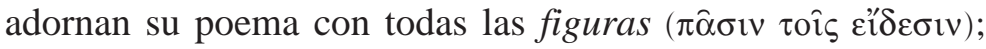
todo lo hacen con metro, con ritmo y con simetrías, y logran conducir las almas de los oyentes, aun cuando fallen en su estilo y en sus ideas $(\dot{\varepsilon} v \theta v \mu \eta \dot{\mu} \mu \alpha \alpha)$. En cambio, continúa, a quienes elaboran discursos nada de esto es posible, sino que deben usar palabras comunes y corrientes ("las palabras de los ciudadanos") y los entimemas necesarios a las acciones. ${ }^{28}$

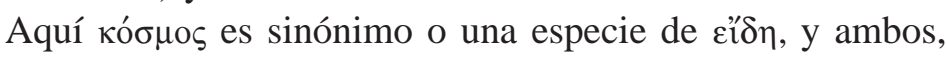
por los ejemplos que pone el autor, equivalen, en plural, a lo que nosotros conocemos como figuras, pero no utiliza la palabra $\sigma \chi \eta ́ p \alpha \tau \alpha$. Estos elementos, además, son diferentes de la $\lambda \varepsilon^{\prime} \xi_{1 \zeta}$ y de los $\dot{\varepsilon} v \theta v \mu \eta \dot{\eta} \mu \alpha \tau \alpha$. Así, el lenguaje figurado es propio de la poesía no de la prosa, lo cual echaría por tierra tanto la idea de que la prosa de Isócrates está recargada de procedimientos ornamentales, como esa otra idea equivocada de que la retórica tiene como característica fundamental el ornato. En realidad, la oposición entre poesía y prosa no es tan radical como parece indicar Isócrates, sobre todo si consideramos el inicio del Panatenaico, donde señala su preocupación por un estilo elevado, y que él mismo ubica su prosa en un lugar más cercano a la poesía que a los discursos judiciales. ${ }^{29}$ Pero la prosa no se basa en el lenguaje que ahora llamamos literario, y si ocupa figuras debe ser con tiento y con mesura.

El enorme descrédito que ha sufrido la retórica se debe fundamentalmente a que ésta usó conscientemente el lenguaje figurado, pero como ese empleo en realidad es propio de la

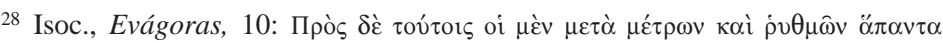

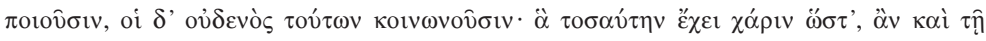

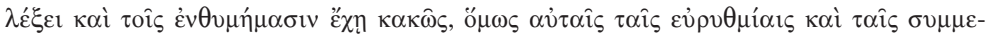

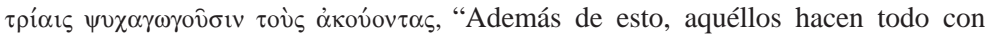
metro y ritmo, mientras que éstos no comparten ninguno de estos medios, los que agradan tanto que, aun cuando estuvieran mal en la forma y en el contenido, sin embargo, seducen a los oyentes mediante esos buenos ritmos y sus simetrías".

${ }^{29}$ Isoc., Panatenaico, 47.
} 
poesía debemos necesariamente concluir que el descrédito se ha basado en una acusación falsa. Los elementos o figuras ( $\left.\varepsilon^{\prime} \delta \eta\right)$ propios de la prosa son la $\lambda \varepsilon^{\prime} \xi_{1 \varsigma}$ y los $\dot{\varepsilon} v \theta v \mu \eta \dot{\mu} \mu \alpha \tau \alpha$. En el Contra los sofistas, Isócrates señala que uno de los aspectos que los discípulos deben aprender del maestro es "adornar mediante entimemas o pensamientos adecuados todo el discurso y hablar con palabras de manera elegante y musical". ${ }^{30}$ La $\lambda \varepsilon^{\prime} \xi_{1 \zeta}$ de la prosa consistiría en la elegancia y la musicalidad.

De cualquier modo, aun cuando las figuras son elementos propios de la poesía, su utilización se extiende a todo tipo de expresión lingüística. La diferencia entonces será de grado. Algunos textos como los discursos epidícticos se acercan más a la poesía, mientras que otros, como la prosa científica, generalmente hace menos uso de ellos.

SEXTo: no existen conceptos para indicar las figuras. El estilo forma parte medular de la retórica de los siglos v y IV. Gorgias fue muy admirado en su tiempo por sus recursos literarios; Isócrates se hizo célebre por el extremado esmero que ponía en la confección de sus discursos; Platón es reconocido como el más grande estilista de todos los escritores griegos antiguos, y Aristóteles y sus epígonos pusieron un especial énfasis en el estudio de los recursos expresivos de la lengua. Aunque el empleo de los recursos del lenguaje que ahora llamamos figuras y tropos era muy frecuente y singular en la época clásica, podemos afirmar que no existió el concepto de ornatus como "adorno vano" en la retórica griega clásica, cuando era la disciplina que tenía como objeto de estudio o de enseñanza los medios de persuasión. En la retórica escolar, se hace equivaler ornatus a la palabra griega кó $\mu$ os, pero ésta no significa sólo "adorno", sino — fundamentalmente-

\footnotetext{
${ }^{30}$ Isoc., Contra los sofistas, 16.
} 
“orden”, en particular el orden político. En Isócrates, кó $\sigma \mu \circ$ aparece con este último sentido, ${ }^{31}$ aunque no es el único. El verbo correspondiente tiene el significado de "armarse" para la batalla. ${ }^{32}$

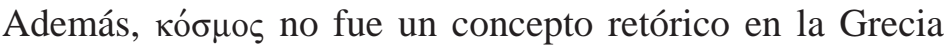
clásica, pues ni siquiera es mencionado en el esencial Lexicon technologiae Graecorum rhetoricae de Ernesti.

Otro término al que se le ha dado el sentido de "ornato" es

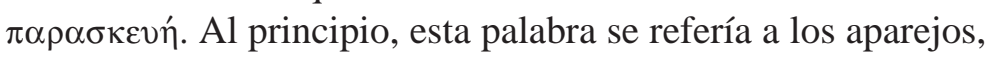
a los útiles de cualquier género. Así, el remo es un instrumento, pero es algo necesario para impulsar las naves. Posteriormente dicho vocablo fue empleado para referirse a diversos fenómenos retóricos, entre ellos el ornatus, pero en su origen, en la época clásica, no tenía este uso. En la terminología retórica existe también la palabra $\sigma \chi \eta \dot{\mu} \mu \alpha \tau \alpha$, pero ésta no aparece con el sentido de "figura" en el más importante maestro de retórica en Grecia: Isócrates, quien, en cambio, utilizaba otros términos para referirse a las figuras, como عí $\delta \eta$ у $\pi$ oเкı $\lambda$ i $\alpha$, pero ambos vocablos son de carácter muy general, de modo que podría afirmarse que el concepto moderno de ornatus no existió en el pensamiento retórico de los griegos del período clásico.

SÉPTIMO: el discurso debe adecuarse al género y al destinatario (lo aptum). Cada orador podía hacer mayor o menor uso de un lenguaje "figurado", y los recursos empleados fueron después utilizados como elementos para definir el estilo de cada quien. Pero la elección de un determinado lenguaje respondía a las circunstancias específicas del caso. No era lo mismo pronunciar un discurso para conmemorar a los muertos caídos durante la guerra reciente, que defender la propia vida ante un amplio colegio de jueces. No era lo mismo un caso de

\footnotetext{
${ }^{31}$ Isoc., Panatenaico, 116.

${ }^{32}$ Isoc., Helena, 23.
} 
asesinato que un caso de robo. El orador debía adaptar su discurso a circunstancias muy particulares, y por ello una caracterización de un autor como grandilocuente o parco es verdadera sólo parcialmente.

Por tanto, resumiendo todo lo anterior, diremos que mientras para los modernos las figuras son la esencia del ornato, para los antiguos el ornatus fue un elemento retórico poco importante. No existía realmente en la retórica griega antigua una parte que se refiriera a las figuras como "adorno", pero sí las incluía como elementos del estilo o $\lambda \varepsilon^{\prime} \xi_{\text {is }}$. Las figuras eran muy importantes en la retórica griega, pero eran contempladas desde otra perspectiva: su función era la persuasión mediante la claridad, el extrañamiento y la elegancia que pueden provocar en los destinatarios. Desde el punto de vista retórico, la finalidad de las figuras no es adornar, sino persuadir o procurar la adhesión del destinatario. Asimismo, las figuras se encuentran en todo tipo de lenguaje, pero el empleo sistemático de éstas es propio de la poesía no del discurso.

La concepción que los griegos tenían acerca de las figuras es muy diferente a la que predomina en la preceptiva literaria tradicional, de modo que es un completo error y una completa terquedad seguir hablando de figuras como si éstas fueran la esencia de la retórica y en ellas se centrara todo el arte de la palabra.

\section{BIBLIOGRAFÍA}

Albaladejo Mayordomo, T., Retórica, Madrid, Síntesis, 1991.

CAmpillo y Correa, N., Retórica y poética. Literatura preceptiva, nts. y adiciones Alfredo Huerta García, México, Editorial Botas, 1945 (1a. ed. de 1872).

Cournot, A. A., Essai sur les fondements de nos connaissances et sur les caractères de la critique philosophique, Paris, L. Hachette, 1912 (1a. ed. de 1851). 
ERnesti, J. C. T., Lexicon technologiae Graecorum rhetoricae congessit et animadv. Illustravit, Lipsiae 1795.

Genette, G., "La retórica restringida", en Investigaciones retóricas II, Buenos Aires, Tiempo contemporáneo, 1974, pp. 203-222.

Knape, J., and D. Till, "Ornatus", en Historisches Wörterbuch der Rhetorik, 6, 2003, coll. 432-440.

Kuenz, P., “Lo 'retórico' o lo puesto al margen”, en Investigaciones retóricas II, Buenos Aires, Tiempo contemporáneo, 1974, pp. 183-202.

LAUSBERG, H., Elementos de retórica literaria: introducción al estudio de la filología clásica, románica, inglesa y alemana, Madrid, Gredos, 1975.

LóPez EIRE, A., Acerca del carácter retórico del lenguaje y de cómo los antiguos griegos lo descubrieron, México, Universidad Nacional Autónoma de México (Bitácora de retórica, 21), 2005.

Nietzsche, F., Escritos sobre retórica, Madrid, Trotta, 2000.

Perelman, Ch., et L. Olbrechts-Tyteca, Traité de l'argumentation. La nouvelle rhétorique, Bruxelles, Presses Universitaires de Bruxelles, 1958. 
